\title{
Estudo de Congruências com Discentes Cegos: Uma Abordagem envolvendo a Sequência FEDATHI e o Método Van Hiele
}

\author{
Elizângela Bezerra Magalhães ${ }^{1}$; Cícero Magérbio Gomes Torres ${ }^{2}$; Jorge Carvalho Brandão ${ }^{3}$
}

\begin{abstract}
Resumo: De que maneira podemos ensinar construções geométricas para discentes cegos incluídos em salas de aula regular? Com o objetivo de responder o questionamento, este artigo apresenta a vivência com 54 sujeitos que participaram de oficinas de matemática adaptada. Num total de 24 graduandos em pedagogia, 22 eram mulheres ( 20 cursando/concludentes) e 02 eram homens (graduados). Dos 30 matemáticos: 18 eram homens (08 cursando/concludentes) e 12 eram mulheres (4cursando/concludentes). No âmbito deste universo, 02 participantes apresentam baixa visão, sendo 01 da matemática e 01 da pedagogia. A justificativa para o termo vivência apresenta-se em função dos participantes terem sido, inicialmente, apresentados aos métodos e as técnicas (como Sequência Fedathi e Van Hiele) e logo em seguida, os participantes puderam colocar em prática, testando-as em salas de aula. Ao longo de todo esse processo, os participantes foram continuamente avaliados. Nesse contexto, e face às vivências que foram realizadas, pode-se perceber que por meio da utilização da Sequência Fedathi e Van Hiele, foi possível ensinar construções geométricas, bem como os conteúdos matemáticos (inclusive os atrelados a aspectos visuais) seja para sujeitos com cegueira quanto sem deficiência visual.
\end{abstract}

Palavras-Chave: Geometria; Cegos; Métodos de Ensino.

\section{Study of congruences with Blind Learners: An Approach involving the FEDATHI Sequence and the Van Hiele's Method}

\begin{abstract}
How can we teach geometric constructions for blind students included in regular class rooms? With the aim of answering the question, this paper presents the experience with 54 subjects who participated in workshops tailored mathematics. Experience because they were presented methods and techniques (such Fedathi Sequence and Van Hiele) and put into practice, testing them in classrooms. Were continuously evaluated. We present some of the buildings and made a use of Fedathi Sequence, among the many experiments to show the possibility of incorporating math concepts (including those based on visual aspects) adapting to blind subjects, as both sighted.
\end{abstract}

Keywords: Geometry; blind; Teaching Methods.

\footnotetext{
${ }^{1}$ Graduada em pedagogia, Mestranda em Educação Brasileira UFC, Psicopedagoga Clinica e Institucional, Especialista em Deficiência Visual. e-mail- lala2magalhaes@gmail.com.

${ }^{2}$ Graduado em Ciências Biológicas pela URCA, Doutorando em Educação Brasileira UFC. e-mail - magerbiomestrado@yahoo.com.br.

${ }^{3}$ Professor UFC, Professor Dr. UFC, Mestrado em Engenharia Civil (Recursos Hídricos) pela Universidade Federal do Ceará (2001), Possui graduação em Matemática pela Universidade Federal do Ceará (1996). e-mail - profbrandao@ufc.br ou adaptacoes@gmail.com.
} 
A Matemática, considerada uma das disciplinas de maior dificuldade no tocante à abstração de conceitos adquiridos, tais como trigonometria e geometria no Ensino Fundamental, para pessoas sem deficiência visual (ou videntes), conforme Brasil (1998), também o é para estudantes com deficiência visual, de acordo com Barbosa (2003) e Abéllan et alli (2005). Sendo assim, começamos a perguntar: como descrever procedimentos geométricos para abordar os mencionados conteúdos matemáticos, contemplando tanto educandos com deficiência visual quanto videntes?

Podemos partir de conhecimentos prévios dos estudantes antes deles entrarem na escola, conforme ressaltam Bicudo (1999) e Lira e Brandão (2013). Todavia, como avaliar se a metodologia abordada de fato é eficiente? Em se tratando de uma metodologia de ensino, como discernir se o docente a utilizará de maneira coerente?

Dentre as metodologias existentes, a Sequência Fedathi (BORGES NETO, et al. 2013) e o método Van Hiele (VAN HIELE, 1986) foram as que melhor conseguimos adaptar durante a realização de oficinas de matemática adaptada tanto para docentes (de matemática), pedagogos e graduandos (de pedagogia e matemática), realizadas durante os meses de agosto de 2013 e março de 2014. No total de 54 participantes foram observados, conforme destacamos na metodologia.

Assim sendo, o objetivo geral deste artigo é avaliar se uma metodologia adaptada para o ensino de geometria para pessoas com deficiência visual incluídas na escola regular, também contempla discentes videntes. Como objetivos específicos: (1) Analisar postura dos docentes frente às adaptações de construções geométricas com régua e compasso. (2) Investigar as congruências entre a Sequência Fedathi e o método Van Hiele.

\section{Revisando a Literatura}

$\mathrm{O}$ aprendizado das crianças começa muito antes delas frequentarem a escola. Qualquer situação de aprendizagem com a qual a criança se defronte na escola tem sempre uma história prévia (VYGOTSKY, 1988).

Sabendo que a interação da criança com o meio, em relação aos estímulos, desempenha um papel ativo no processo de aprendizagem, segue-se que a atitude desenvolvida na criança durante os primeiros anos de escolarização determinará o seu crescimento intelectual e o futuro aproveitamento do seu potencial criador (BARBOSA, 2003).

Assim, visando o desenvolvimento e aprimoramento dos estímulos dados às crianças deficientes visuais, para o ensino de Geometria, toma-se como base uma Geometria intuitiva, em que 
as crianças a partir da Pré-Escola devem realizar inúmeras experiências tanto com o corpo quanto com objetos, visando o desenvolvimento do senso espacial.

É possível relacionar atividades cotidianas de alunos deficientes visuais fazendo uso conjunto de técnicas de Orientação e Mobilidade com conceitos de Geometria Plana, de modo que o conhecimento adquirido com o próprio corpo venha a ser abstraído, conforme Brandão (2004).

No próximo tópico, tratamos da avaliação. Com efeito, precisamos de um norte me relação à metodologia utilizada.

\section{Avaliação}

Por que avaliar? Conforme Hoffmann (1994) a avaliação tem como objetivo favorecer ações educativas as quais possibilitem novas descobertas. A avaliação destina-se à melhoria do ciclo de vida. Por conseguinte, conforme Luckesi (1994), a avaliação deve ter um caráter diagnóstico, criando bases para tomadas de decisões na perspectiva de maior satisfatoriedade nos resultados.

Tanto Luckesi (1994) quanto Hoffmann (1994) salientam a avaliação como um instrumento subsidiário da prática educativa. Assim sendo, para que haja uma avaliação da aprendizagem satisfatória é preciso coletar, analisar e sintetizar as condutas dos educandos frente à determinada atividade dirigida pelo professor.

Neste trabalho as atividades dirigidas são confecções de situações-problema em oficinas realizadas com educadores e graduandos. Jogos com tangram servem de referencial para construções geométricas.

A avaliação informa ao professor o que foi aprendido pelo estudante. Longe de ser apenas final do processo de ensino, a avaliação se inicia quando os estudantes põem em jogo seus conhecimentos prévios e continua a se evidenciar durante toda situação escolar (BRASIL, 1998).

\section{Perguntas que norteiam a avaliação da aprendizagem}

Há quatro perguntas que devem nortear uma boa avaliação da aprendizagem, aconteça ela no ensino fundamental, médio ou superior (BARBOSA, 2006).

\section{$1^{a}$ - Quem avalia?}

$\mathrm{Na}$ escola tradicional os papéis ficavam bem definidos: cabia ao professor a autoridade suprema da avaliação, cujos resultados eram inquestionáveis, e o aluno era o "objeto" da avaliação. 
Perrenoud (1999) afirma que a avaliação fica em conflito entre duas lógicas, diametralmente opostas: normativa e formativa. A avaliação normativa, colocada a serviço da seleção, apenas cria hierarquias de excelência, pois "os alunos são comparados e depois classificados em virtude de uma norma de excelência, definida no absoluto ou encarnada pelo professor e pelos melhores alunos". (PERRENOUD, 1999, p. 11)

A avaliação formativa, colocada a serviço das aprendizagens, torna-se mais uma estratégia pedagógica de luta contra o fracasso e as desigualdades. Inclui o cuidadoso conhecimento da aprendizagem dos alunos e a aplicação de estratégias diferenciadas para cada grupo.

Não se trata, no entanto, de descuidar alguns aspectos formais da avaliação, que precisam ser cumpridos "[...] a avaliação formativa não dispensa os professores de dar notas ou de redigir apreciações, cuja função é informar os pais ou a administração escolar sobre as aquisições dos alunos, fundamentando a seguir decisões de seleção ou de orientação". (PERRENOUD, 1999, p. 16).

Existem, portanto, três formas de avaliação, que não retiram do professor a responsabilidade de realizá-la, mas que a tornam compartilhada, mais democrática e mais aproximada da segunda modalidade de que fala Perrenoud. Dependendo da modalidade, varia a resposta à primeira pergunta "Quem avalia?". São elas (BARBOSA, 2006):

- Hetero-avaliação: consiste na valorização do rendimento escolar feita por pessoas distintas do próprio aluno, fundamentalmente o professor.

- Auto-avaliação: expressa o juízo de valor que o aluno faz do rendimento educativo que teve.

- Avaliação mista ou co-avaliação: tem lugar quando o docente e o aluno avaliam em conjunto as atividades ou o rendimento deste; quando ambos analisam determinadas tarefas ou rendimentos. Pode incluir, como agentes avaliadores, outros alunos, no caso de atividades realizadas em grupo.

Sempre que o professor abre mão de monopolizar o poder da avaliação, compartilhando-o com outras pessoas, o processo se torna mais democrático e o comprometimento e a participação de todos, ao avaliarem e serem avaliados, crescem consideravelmente.

\section{$2^{a}$ - Quando avaliar?}

A resposta é imediata e única: sempre.

Se considerarmos a aprendizagem como um processo contínuo, global e cumulativo, as avaliações pontuais sempre incorrem em sérios riscos de erro. A avaliação deve ser, portanto, contínua.

Isto fica mais claro, ao ser feito destaque das quatro modalidades de avaliação do rendimento acadêmico dos alunos:

- Diagnóstica - de início de processo, permite o conhecimento inicial do aluno, dos conceitos que já possui, do seu estilo de aprendizagem. 
- Formativa - acompanha o processo, permitindo as correções e ajustes necessários.

- Somativa - a única realizada no modelo tradicional de Educação, que permite a classificação dos alunos de acordo com padrões estabelecidos previamente.

- Meta-avaliação - tem como foco o próprio sistema de avaliação utilizado, sua validade e fidedignidade.

Avaliação contínua refere-se a este ciclo de avaliações que se articulam permitindo, ao fim, regular e corrigir as falhas do próprio sistema de avaliação utilizado.

Destaca-se, neste processo de continuidade da avaliação, a modalidade formativa. Realizada durante o processo de aprendizagem, torna-se mais um instrumento para aprimorar sua realização.

\section{$3^{a}$ - Como avaliar?}

Quanto às estratégias avaliativas, podemos propor um saudável "vale-tudo" metodológico. Tudo o que o aluno produz pode demonstrar a aprendizagem realizada e, consequentemente, ser avaliado.

Considerando-se as situações formais de avaliação, planejadas pelo professor (provas, testes, atividades individuais ou grupais) e as situações informais, ocorridas no cotidiano da sala de aula, e que também se prestam para esta finalidade (principalmente quanto à avaliação formativa).

É conveniente lembrar, ainda, que as expressões em variadas linguagens devem ser consideradas para fins avaliativos, complementando aquelas que são propostas por escrito, tão comuns em nossa realidade (BARBOSA, 2006).

\section{$4^{a}$ - Para que avaliar?}

Busca-se:

- Verificar o ritmo e os estilos de aprendizagem dos alunos.

- Realimentar o processo ensino-aprendizagem, permitindo efetuar correções.

- Identificar os conteúdos e objetivos mais importantes.

- Detectar e corrigir os erros mais freqüentes.

- Comparar o desempenho demonstrado pelos alunos, com os objetivos inicialmente definidos.

- Verificar a possibilidade dos alunos atingirem estágios posteriores de aprendizagem.

- Avaliar o próprio sistema de avaliação utilizado.

- Verificar a adequação das atividades e estratégias.

Feitas tais colocações em relação a avaliação, não podemos esquecer dos discentes que possuem dificuldades de aprendizagem neste campo do saber 


\section{Dificuldades de Ensino-Aprendizagem da Matemática}

No tocante às dificuldades de compreensão e de desenvolvimento de raciocínio lógico do ensino de Matemática, de um modo geral, conforme Brasil (1998), falta relacionar aquilo que se aprende na escola formal com aquilo que o estudante vivencia. A partir do concreto, em um processo gradativo, o aluno compreende problemas do cotidiano apresentados de modo abstrato.

Lima e Silva (2004) salientam que ensinar Matemática, em qualquer série e independente dos conteúdos ministrados, não é repassá-los no quadro e resolver exercícios que servirão de modelos para provas. O conhecimento matemático é baseado em um raciocínio lógico. E como a Matemática foi se desenvolvendo a partir do cotidiano, por qual motivo não continuar realizando a relação daquilo que se aprende com aquilo que se vive?

Desta forma, uma das dificuldades da aprendizagem de Matemática, e em particular do Desenho Geométrico, está na forma como o professor aborda os conteúdos, quaisquer que sejam, não lhes dando significado prático nem os apresentando de forma que o estudante desenvolva um raciocínio lógico e crítico.

E só se aprende matemática para aplicar no cotidiano?

Conforme os Parâmetros Curriculares Nacionais (BRASIL, 1998), destaca-se que o aprendizado de Matemática no Ensino Fundamental deve levar o aluno a perceber que a Matemática estimula o espírito investigativo e o desenvolvimento da capacidade para resolver problemas. Também deve apresentar resultados e sustentar argumentos por meio das linguagens orais e escrita.

Assim sendo, ressalta-se a valorização do raciocínio lógico.

Em relação aos jogos, o que estes revelam ao professor?

Caso não sejam realizados como obrigação, os jogos propiciam a simulação de situaçõesproblema que exigem soluções imediatas. Isso estimula o planejamento de ações e possibilita a construção de uma atitude positiva diante dos erros, uma vez que as situações se sucedem rapidamente e podem ser corrigidas de forma natural, no decorrer da ação, sem deixar marcas negativas (BICUDO, 1999).

Por sua vez, há interesse do professor em realizar jogos e utilizar materiais concretos para facilitar a aprendizagem da Matemática? Assim, tem-se:

\section{A formação do professor de Matemática}

Uma das tarefas de qualquer professor é trabalhar com os educandos a rigorosidade metódica com que devem se "aproximar" dos objetos cognoscíveis. E esta rigorosidade metódica exige tanto do 
educador quanto do educando uma postura de investigação, de criação e com humildade (FREIRE, 2005).

Como deve ser estruturada a formação inicial e continuada do professor para que possa contribuir no desenvolvimento de uma cultura profissional, onde estarão presentes a reflexão crítica, a investigação, o trabalho coletivo e a autonomia? (BICUDO, 1999).

No tocante aos cursos, os futuros docentes têm disciplinas tanto na área pedagógica, como Psicologia da Aprendizagem, Didática, entre outras, quanto disciplinas de cursos de bacharelado, como Cálculo Diferencial e Integral, Variável Real etc. Deste modo, o aluno é preparado para o raciocínio abstrato, após desenvolver sensos lógico e crítico.

Sendo desenvolvidos raciocínios lógico e abstrato, espera-se que ao chegarem na disciplina de Prática de Ensino em Matemática, os discentes sejam capazes de resolver e criar situações-problema, bem como terem discernimento de contornar algumas dificuldades de aprendizagem em determinados conteúdos, como soma de frações, trigonometria etc. (BICUDO, 1999).

Situações-problema servem para trabalhar a rigorosidade metódica (FREIRE, 2005). Elas envolvem mais que a resolução de operações como a soma ou a multiplicação. Problemas tidos como não rotineiros são baseados em textos bem montados que possibilitam vários caminhos para sua solução (BRASIL, 1998). Cada aluno o resolve de uma maneira, de acordo com seu conhecimento prévio e organização de raciocínio (BICUDO, 1999).

No tocante à formação do professor, são considerados três eixos de investigação da perspectiva do desenvolvimento profissional: Ensino reflexivo; Trabalho colaborativo e Momentos marcantes (BICUDO, 1999).

Ensino reflexivo é a capacidade do professor, enquanto profissional do ensino, implicar-se em uma reflexão crítica e radical do processo educativo, analisando o significado de sua ação social e docente.

Trabalho colaborativo é o ato de trabalhar em conjunto com os outros professores, visando a interdisciplinaridade. Momentos marcantes são fatos ou atos que fazem o professor sentir-se valorizado, contribuindo de forma positiva no seu trabalho docente.

A seguir, abordamos de maneira breve as metodologia de Van Hiele e a Sequência Fedathi:

\section{Sequência FEDATHI e Van Hiele}

A teoria de Dina e Peter van Hiele (1986) desenvolvida nos anos 50 do século XX, propõe uma progressão na aprendizagem da Geometria através de cinco níveis cada vez mais complexos. Esta progressão é determinada pelo ensino. Assim, o professor tem um papel fundamental ao definir as 
tarefas adequadas para os alunos progredirem para níveis superiores de pensamento. Sem experiências adequadas, o seu progresso através dos níveis é fortemente limitado.

Conforme teoria há cinco níveis de aprendizagem da Geometria: visualização (nível 0), análise (nível 1), ordenação (nível 2), dedução (nível 3) e rigor (nível 4). Na visualização os alunos compreendem as figuras globalmente, isto é, as figuras são entendidas pela sua aparência.

Os conceitos geométricos são vistos como entidades totais, e não como entidades que têm componentes ou atributos. As figuras geométricas, por exemplo, são reconhecidas por sua forma como um todo, isto é, por sua aparência física, não por suas partes ou propriedades. Neste nível, alguém consegue aprender um vocabulário geométrico, identificar formas específicas e, dada uma figura, consegue reproduzi-la. Contudo, por exemplo relacionando retângulos e quadrados, não reconheceria que as figuras têm ângulos retos e que lados opostos são paralelos,.

$\mathrm{Na}$ análise os aprendizes entendem as figuras como o conjunto das suas propriedades; por exemplo, através da observação e da experimentação, os alunos começam a discernir as características das figuras. Surgem propriedades que são utilizadas para conceituar classes de configurações. Desta feita, reconhece-se que as figuras têm partes, sendo assim reconhecidas por tais partes. Após usarem vários exemplos de paralelogramos, os alunos poderiam fazer generalizações para a referida classe. Todavia, os alunos deste nível ainda não são capazes de explicar relações entre propriedades, não veem inter-relações entre figuras e não entendem definições.

$\mathrm{Na}$ ordenação, também identificada como dedução informal, os estudantes ordenam logicamente as propriedades das figuras; fazendo inter-relações. Já são capazes de deduzir propriedades de uma figura e reconhecer classes de figuras. As definições têm significado. Exemplificando: um quadrado é um retângulo porque tem todas as propriedades de um retângulo.

$\mathrm{Na}$ dedução os discentes entendem a Geometria como um sistema dedutivo; postulados, teoremas e definições já passam a ser compreendidos. Há possibilidades de entender e desenvolver uma demonstração de mais de uma maneira; compreendem condições necessárias e suficientes; são capazes de fazer distinções entre afirmações e recíprocas.

E no rigor os alunos estudam diversos sistemas axiomáticos para a Geometria de forma abstrata.

A teoria de Van Hiele sugere que o pensamento geométrico evolui de modo lento desde as formas iniciais de pensamento até as formas dedutivas finais onde a intuição e a dedução se vai articulando. As crianças começam por reconhecer as figuras e diferenciá-las pelo seu aspecto físico e só posteriormente o fazem pela análise das suas propriedades.

O modelo visa fornecer uma compreensão daquilo que há de específico em cada nível de pensamento geométrico. Destaca-se que Van Hiele identificaram algumas generalidades que caracterizam o modelo. 
É sequencial, pois uma pessoa deve necessariamente passar pelos vários níveis, sucessivamente. Para compreender determinado nível, o discente precisa assimilar as estratégias dos níveis precedentes. $\mathrm{O}$ avanço, progressão ou não progressão de um nível para outro, depende mais do conteúdo e dos métodos de instrução recebidos do que a idade. Nenhum método de ensino permite ao aluno avançar de um nível para outro sem a devida compreensão.

Os objetos inerentes a um nível tornam-se os objetos de ensino no nível seguinte. Por exemplo, no primeiro nível apenas a forma é percebida. A figura, que é percebida por suas propriedades, só é caracterizada no segundo nível.

A linguística também é uma generalidade porque ressalta que cada nível tem seus próprios símbolos linguísticos e seus próprios sistemas de relações que ligam esses símbolos. Desta feita, uma relação que é "correta" em um determinado nível pode ser modificada em outro nível. Por exemplo, uma figura que pode ter mais de um nome, um quadrado é um retângulo e também é um paralelogramo, só é percebida pelo estudante que se encontra no terceiro nível.

Destaca-se que caso um aluno esteja em certo nível e o curso em um nível diferente, o aprendizado bem como o progresso talvez não se verifiquem. Combinação inadequada é denominada esta generalização do modelo. De acordo com Van Hiele, como são as fases do aprendizado? São propostas cinco fases, a saber: interrogação/informação, orientação dirigida, explicação, orientação livre e integração.

$\mathrm{Na}$ fase de interrogação/informação professor e alunos conversam e desenvolvem atividades envolvendo objetos de estudo no respectivo nível. Fazem-se observações, levantam-se questões e introduz-se um vocabulário específico do nível.

$\mathrm{Na}$ orientação dirigida os discentes exploram tópicos de estudos através do material que o professor ordenou em sequência. Tais atividades revelarão gradualmente aos alunos as estruturas características desse nível. Desta forma, grande parte do material será pequenas tarefas com o intuito de suscitar respostas específicas.

Em relação à fase de explicação, com base em experiências anteriores, discentes expressam e trocam suas visões emergentes sobre as estruturas que foram estudadas. Mínimo é o papel do docente em virtude de o mesmo apenas orientar os alunos no uso de uma linguagem adequada.

$\mathrm{Na}$ orientação livre são realizadas tarefas em aberto ou que possuem várias maneiras de serem concluídas. O aluno ganha experiência ao descobrir várias formas de abordar determinada situação problema. E na integração os aprendizes reveem e sumarizam o que aprenderam com o objetivo de formar uma visão geral da nova rede de objetos e relações.

Um exemplo de ilustração das fases de aprendizagem para o conceito de retângulo: 
Informação/interrogação: O professor mostra aos alunos diversos retângulos e pergunta-lhes se são ou não retângulos. Os alunos são capazes de dizer se uma dada figura é ou não retângulo, mas as razões apresentadas serão apenas de percepção visual.

Orientação guiada: Realizam-se outras atividades sobre retângulos. Por exemplo, dobrar um retângulo segundo os seus eixos de simetria; desenhar um retângulo no geoplano que tenha as diagonais iguais, construir um maior e um menor.

Explicitação: As atividades anteriores são seguidas por uma discussão entre os alunos sobre o que descobriram. Orientação livre: O professor coloca o problema de construir um retângulo a partir de dois triângulos. Integração: Os alunos reveem e resumem o que aprenderam sobre as propriedades do retângulo. O professor ajuda a fazer a síntese.

Para ser adequado, isto é, para ter em conta o nível de pensamento dos alunos, o ensino da Geometria no Ensino Fundamental deve ter como preocupação ajudá-los a progredir do nível visual para o nível de análise. Assim, eles devem começar por identificar, manipular (construir, desenhar, pintar, etc.) e descrever figuras geométricas.

De que forma o método Van Hiele pode ser adequado para pessoas com deficiência visual? Destaca-se que uma pessoa cega apesar de não ver determinada figura esta pode ser representada por peças de E.V.A., papelão ou quaisquer outros materiais concretos, satisfazendo o primeiro nível, a visualização, do método Van Hiele.

Em relação à Sequencia Fedathi, breve resumo a seguir:

Tomada de posição: Nesta etapa o professor estabelece algumas regras com objetivo de conduzir os trabalhos dos alunos, aqui o professor passa a fazer parte do grupo como um ser reflexivo e questionador. Nesta fase o professor oferece uma situação desafiadora onde o conteúdo implícito no desafio deverá ser aprendido até o fim do processo.

Maturação: Nessa etapa os discentes e docentes discutem sobre a situação problema que foi apresentada, os estudantes procuram compreender os problemas e as possíveis intervenções que auxiliem a solução do problema.

Solução: Nesse momento os estudantes organizam suas hipóteses a fim de que possam chegar a solucionar o problema, procuram entender e compreende-lo. É importante lembrar que os estudantes têm a liberdade de demonstrar suas hipóteses, sejam por gráficos, tabelas, cálculos, ou verbalmente sendo importante que o professor analise com o estudante as formas que foram apresentadas.

Prova: Nessa fase o professor apresenta as hipóteses apresentadas pelos alunos e faz uma relação dessas hipóteses aos conceitos matemáticos que serão aprendidos. Nessa fase o "novo" deverá ser aprendido significativamente pelo aluno.

Percebemos muitas semelhanças entre o modelo proposto pelos Van Hiele e a Sequência Fedathi. 


\section{Metodologia}

\section{Desenho do Estudo}

O estudo consistiu no acompanhamento de três oficinas de matemática adaptada, cada uma com 12 h/aula de duração e máximo de 20 participantes por oficina. As vivências aconteceram com a participação de 54 sujeitos. Desses 24 eram graduandos em pedagogia desse total são: 22 mulheres (20 cursando já na fase de conclusão do curso) e 02 homens ( graduados) e 30 matemáticos: 18 homens( 08 cursando na fase de conclusão) e 12 mulheres (4 cursando concluindo curso). Desses 54 Dois (02) participantes tinha baixa visão, 01 aluno da matemática e 01 aluna da pedagogia. Cada uma das oficinas teve três encontros com três horas cada uma, em dias de sábado. As outras três horas foram de observações em sala de aula. Realizadas entre agosto de 2013 e março de 2014. Desses 54 participantes (seis desistiram).

\section{Característica do Estudo}

O estudo consiste de pesquisa qualitativa (LUDKE, 1986), enfatizando observações participantes bem como entrevistas não-diretivas com o intuito de averiguar se os discentes sabiam o que estavam construindo geometricamente e se tinham condições de lecionar, na Matemática do Ensino Fundamental, técnicas de Desenho Geométrico para alunos com deficiência visual.

\section{Local da pesquisa}

A pesquisa foi realizada em dois locais: no primeiro na realização de cada oficina, 6 h/aulas

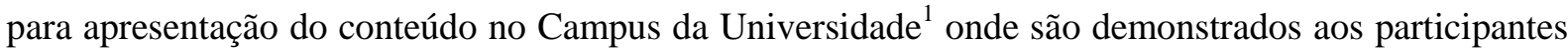
métodos e técnicas úteis para ambos os alunos (tanto com deficiência visual quanto videntes), adaptando a mencionada disciplina.

No segundo local, uma escola onda há discentes com deficiência visual incluídos, foram realizados acompanhamentos em três aulas (com 50 minutos cada uma). A primeira aula consistia em observação e as demais em intervenção.

Retornamos para o primeiro local para realizar avaliação da oficina, contemplando tanto as teorias apresentadas quanto as vivências realizadas.

Deste modo, os sujeitos da pesquisa foram:

\footnotetext{
${ }^{1}$ Aqui não identificada para preservar anonimato dos autores
} 


\section{Sujeitos da pesquisa}

Num de total de 54 sujeitos. Desses 24 eram graduandos em pedagogia desse total são: 22 mulheres (22 cursando já na fase de conclusão do curso) e 02 homens (graduados) e 30 matemáticos: 18 homens (06 cursando na fase de conclusão) e 12 mulheres (4 concluindo curso). Desses 54; Dois (02) participantes tinha baixa visão, 01 aluno da matemática e 01 aluna da pedagogia.

Em termos quantitativos, a primeira oficina foi destinada aos pedagogos (10 formados e 10 graduandos). A segunda oficina contemplou matemática (10 graduados e 10 graduandos), nesta, tivemos a evasão de quatro professores de matemática. Por fim, na terceira, dividimos proporcionalmente as vagas: cinco para cada grupo (pedagogos, matemáticos, graduandos em pedagogia e graduandos em exatas).

$\mathrm{Na}$ última oficina incluímos discentes da área de Exatas, como Física e Química. Três estudantes de Física participaram. Nesta terceira oficina, dois participantes desistiram: um pedagogo e um estudante de pedagogia.

\section{Instrumentos da pesquisa}

Recursos pedagógicos, tais como jogos e materiais concretos (tangram, material dourado etc.), úteis tanto para alunos com deficiência visual quanto videntes; confecção e resolução de situaçõesproblema propostas pelos discentes ou professor.

\section{Procedimentos}

Em um primeiro momento foi apresentado o conteúdo da disciplina. Nesta apresentação, destacou-se a geometrografia plana, que é a arte de fazer construções geométricas de maneira abstrata.

Em um segundo momento, cada aluno foi entrevistado e solicitado a resolver e propor situações-problema. Neste momento foram reapresentados conceitos para estudantes cegos, já apresentados em sala de aula, tendo como base a Orientação e Mobilidade, conforme Lira e Brandão (2013), e os alunos foram continuamente avaliados, sendo observados seus avanços e suas dificuldades.

Dentre os materiais concretos inseridos destaca-se o tangram. Diante das formas apresentadas, alunos vendados descreviam e, em seguida, tentavam reproduzir no papel aquilo que imaginavam.

Exemplificando:

Observação: Para realizar construções com pessoas com deficiência visual deve-se analisar o grau da deficiência. Se cego, o uso de instrumentos adaptados (como réguas e esquadros milimetrados em Braille) bem como figura em alto-relevo, produzidas com cartolina, barbante etc. (para analisar contornos, medidas, etc.) é de grande valia. Vale ressaltar que o modo de usar os instrumentos é o mesmo para todos os praticantes (com ou sem deficiência visual). 


\section{1) Traçar uma reta perpendicular a uma outra reta dada.}

1. Trace uma reta $r$ qualquer. Coloque um dos lados de um esquadro em $r$ e trace no outro lado uma reta $s$. Como os lados são perpendiculares, segue-se que $r$ e $s$ são perpendiculares.

Caso você não tenha esquadros, faça o seguinte:

1. Trace uma reta qualquer $r$ e marque um ponto $A$ nesta reta.

2. Com o compasso em uma abertura qualquer com centro em $A$, marque os pontos $B$ e $C$, à direita e à esquerda de $A$ em $r$, respectivamente.

3. Com centro em $B$ e raio (abertura do compasso) um pouco maior que o raio anterior, trace um arco acima e abaixo de $r$. Faça a mesma coisa com $C$, considerando o mesmo raio.

4. Unir as interseções dos arcos. Tal reta (de interseção) é perpendicular à reta $r$.

Justificativa: Chamando de $D$ e $E$ as interseções, construímos o losango $B C D E$, lembrando que as diagonais de um losango são perpendiculares entre si.

\section{2) Traçar uma reta paralela a uma outra reta dada.}

1. Trace uma reta $r$ qualquer. Coloque um dos lados de um esquadro em $r$ e trace no outro lado, com o outro esquadro tendo um de seus lados colocado junto ao primeiro esquadro, trace uma reta $s$ no lado do segundo esquadro que não está "colado". Como os lados são perpendiculares, segue-se que $r$ e $s$ são paralelas.

Sem esquadros...

2. Sejam $A$ um ponto e $r$ uma reta dada. Traçar um arco com centro em $A$ e raio qualquer até interceptar $r$, no ponto $B$.

3. Com centro em $B$ e mesmo raio anterior, obter $C$, em $r$.

4. Com centro em $C$, obter a distância de $C$ até $A$ (com o compasso). Com tal raio e centro em $B$ marque um arco até interceptar o arco feito por $A$, em $D$.

5. A reta que passa pelos pontos $A$ e $D$ é paralela à reta $r$.

Conforme os Parâmetros Curriculares Nacionais (PCN), "não é a aprendizagem que deve se ajustar ao ensino, mas sim o ensino deve potencializar a aprendizagem". (BRASIL, 1998).

Agora, vamos indicar uma vivência da Sequência Fedathi com Van Hiele, pois várias foram as situações observadas, o que não dá para indicar aqui por ocasião da limitação de páginas:

Foi observado um sujeito cego congênito. Utilizamos o termo congruência atrelado à Geometria Plana. Mais precisamente, congruência de triângulos. No tocante ao sujeito observado, o referido assunto foi analisado (e vivenciado) no segundo encontro.

Para leitor leigo, conforme Dolce e Pompeu (2005), definimos que um triângulo é congruente (cujo símbolo é $\equiv$ ) a outro se, e somente se, for possível estabelecer uma correspondência entre seus vértices de modo que 
- Seus lados são ordenadamente congruentes aos lados do outro e

- Seus ângulos são ordenadamente congruentes aos ângulos do outro.

Assim sendo, a tomada de posição consistiu na realização de um pré-teste. Com efeito, saber conhecimentos prévios do discente.

Consistiu das seguintes questões:

1) O que percebes em relação aos triângulos que tens (fornecemos quatro triângulos de madeira para o discente, sendo dois triângulos isósceles, que eram os únicos congruentes, um triângulo retângulo e um triângulo equilátero ${ }^{2}$ ).

2) Sabemos, de nosso encontro passado, que a congruência de segmentos de reta é uma noção primitiva que satisfaz três postulados. Quais são os postulados?

3) Defina congruência entre triângulos.

O objetivo de cada questão era:

(1) Realizar sobreposição entre os triângulos para identificar os "parecidos ou iguais" (côngruos). Com efeito, analisar se sujeito estava conseguindo realizar uma ligação entre os conhecimentos apresentados entre os encontros.

(2) Caracterizar os postulados, que poderiam ser argumentados via manipulação de objetos concretos, como canetas de mesmo tamanho: Reflexiva, $\overline{A B} \equiv \overline{B A}$; Simétrica, se $\overline{A B} \equiv \overline{C D}$ então $\overline{C D} \equiv \overline{A B} ;$ Transitiva, se $\overline{A B} \equiv \overline{C D}$ e $\overline{C D} \equiv \overline{E F}$ então $\overline{A B} \equiv \overline{E F}$

(3) Conceituar triângulos congruentes a partir dos segmentos (lados) e ângulos. Esperava-se, pelo menos, que discente argumentasse que havia relação entre os lados.

Somente a primeira questão foi respondida de maneira satisfatória. A segunda argumentou que eram canetas (segmentos) iguais. Chegou até a colocar uma ao lado da outra com as "pontas" opostas. Não respondeu a terceira questão.

Antes de prosseguir com a Sequencia Fedathi, um questionamento natural que o(a) leitor(a) pode fazer é: há utilidade do assunto congruência para pessoas com cegueira?

Sim, principalmente em atividades de Orientação e Mobilidade que, resumidamente, podem ser entendidas como as técnicas utilizadas para uma locomoção independente.

Por exemplo: Ao treinar em um quarteirão de formato retangular, suponha que as ruas $M$ e $N$ sejam paralelas. Mesma suposição para as ruas $R$ e $S$. Caso o aluno esteja na esquina das ruas $M$ e $R$ e deseje se locomover até a esquina das ruas $N$ e $S$, qual percurso deve realizar, para ter a menor distância? Justifique. (Ou seja, menor distância entre os pontos A e B sem ser em diagonal, por causa das casas ou obstáculos).

\footnotetext{
2 Fica um questionamento para você, nobre leitor(a): todo quadrado é retângulo ou todo retângulo é quadrado? Todo triângulo isósceles é equilátero ou todo equilátero é isósceles? Este questionamento será mais adiante respondido pelo próprio discente.
} 
Neste caso, é compreender que um retângulo possui lados opostos iguais. Portanto, tanto faz o percurso. Vale ressaltar que, após serem vivenciados os percursos, são construídas maquetes.

Assim sendo, a maturação consistiu justamente em vivenciar, através de atividades de Orientação e Mobilidade, os postulados (reflexiva, simétrica e transitiva).

$\mathrm{Na}$ sala onde estávamos formato de um retângulo com oito metros de frente por dez metros de fundo, com auxílio dos outros participantes, colocamos as cadeiras no fundo da sala de tal modo que formássemos um quadrado de lado oito metros.

Mas, tal informação não foi repassada para o discente (que a sala agora estava no formato de um quadrado). Dando passos de mesmo tamanho e se locomovendo ao lado das paredes (e cadeiras que formavam o quarto lado), ele percebeu que os quatro lados eram de mesmo tamanho.

Associando lado com seguimento, discente era indagado sobre os postulados, agora vivenciado. Em seguida, representou sobre uma das cadeiras que estavam no fundo da sala, com auxílio de canetas de mesmo tamanho, o novo formado da sala.

Novamente fornecendo os quatro triângulos ao sujeito, ele agora respondeu quais relações tinham a partir dos seguimentos (lados). Outras figuras foram dadas, no caso, as sete peças de um tangram de madeira.

Solicitamos que construísse triângulos, após identificar cada um dos sete polígonos que formam o tangram ${ }^{3}$, com: (1) duas peças; (2) três peças; (3) quatro peças (após construção, comparou com seus colegas para averiguar se estavam usando as mesmas peças - de que forma comparou? Simples, tateando); (4) cinco peças; (5) Sete peças.

A solução do questionamento, em resumo: o que são triângulos congruentes, foi obtida parcialmente quando associou as medidas dos segmentos. Isto é, eles devem ter segmentos (lados) parecidos (ordenadamente) côngruos.

Fizemos uma pequena intervenção: entre o braço, o cotovelo e o antebraço podemos formar o que? De imediato ele associou ângulo, pois faz parte do seu contexto social um ângulo em torno de $120^{\circ}$ para iniciar uma locomoção independente ${ }^{4}$.

Desta feita, ele conseguiu associar ao conceito a necessidade de inserir a palavra ângulos. Sua definição foi assim argumentada: Dois triângulos são côngruos quando possuem lados e ângulos na mesma posição côngruos.

E a prova consistiu em perguntar ao discente quais os casos de congruência ele consegue detectar. Isto é, argumentamos que para que dois triângulos sejam congruente não é necessário verificar todos os lados e todos os ângulos. Quantas informações servem, perguntamos?

Por tentativas e erros, ele concluiu que três eram suficientes (duas não davam certo, quatro implicava quase que automaticamente em seis entes para analisar). Em seguida, perguntamos quais.

\footnotetext{
${ }^{4}$ Ângulo entre o braço, cotovelo e antebraço.

87 Id en line Revista de Psicologia. Ano 8, No. 23, Julho/2014 - ISSN 1981-1179. Edição eletrônica em http://idonline.emnuvens.com.br/id
}

${ }^{3}$ Vários tangrans foram dados para o discente e outros participantes para realizar as construções. 
Ele indicou três ${ }^{5}$ : (1) Lado - Ângulo - Lado; (2) Ângulo - Lado - Ângulo e (3) Lado - Lado - Lado.

Para alguém com pouca vivência na matemática, em particular geometria plana, suas indicações provam que ele conseguiu definir e estabelecer casos de congruência (mesmo com seu próprio linguajar, mas sem "ferir" a essência da matemática).

Vale ressaltar que um quarto caso de congruência não foi por ele identificado: Lado - Ângulo - Ângulo. Mas isso não invalida as "congruências" entre a Sequência Fedathi e o método dos Van Hiele.

Como expectativas (ou contribuições para o futuro), pode-se tentar apresentar outros conteúdos da geometria plana e até espacial.

Ele respondeu de maneira satisfatória o questionamento: todo quadrado é retângulo ou todo retângulo é quadrado? Para tanto, basta perceber que o quadrado tem uma propriedade a mais: a exigência dos quatro lados iguais...

\section{Resultados /Considerações}

Dos 54 sujeitos acompanhados, percebeu-se que 37 tiveram desempenho satisfatório (sabiam fazer e explicar construções geométricas bem como confeccionar situações-problema).

Como considerações finais, é interessante apresentar este artigo para professores de disciplinas de Prática de Ensino em Matemática de Universidades, para que os dados sejam analisados e outras turmas sejam testadas.

\section{Referências}

ABBELLÁN, R. M. et al. Discapacidad visual: desenrollo, comunicación e intervención. Madri. Grupo Editorial Universitario. 2005

BARBOSA, P. M. O estudo da geometria. Benjamin Constant, Rio de Janeiro n. 23, p. 14-22, agosto de 2003.

BARBOSA, Jane. A prática pedagógica no ensino superior. Rio de Janeiro: UCB/CEP, 2006.

BAUMEL, Roseli C. Rocha de C. et al. Integrar e Incluir - desafio para a escola atual. São Paulo: FEUSP. 2001.

\footnotetext{
${ }^{5}$ Para facilitar manipulação, os outros participantes confeccionaram em cartolina triângulos, usando como moldes os triângulos feitos com as peças dos tangrans.
}

88 Id en line Revista de Psicologia. Ano 8, No. 23, Julho/2014 - ISSN 1981-1179. Edição eletrônica em http://idonline.emnuvens.com.br/id 
BICUDO, Maria A. V. (Org.) Pesquisa em educação matemática: concepções e perspectivas. São Paulo: UNESP. 1999.

BORGES NETO. Herminio et al. Sequência Fedathi: uma proposta pedagógica para o ensino de matemática e de ciências. Fortaleza: Edições UFC, 2013

BRANDÃO, Jorge C. Geumetria $=\mathrm{Eu}+$ Geometria. Benjamin Constant, Rio de Janeiro, n. 28, p.1621, agosto de 2004.

BRASIL. MEC. Parâmetros Curriculares Nacionais. Temas Transversais. Brasília: MEC/SEF. 1998.

DOLCE e POMPEU. Fundamentos de matemática elementar, v.9. São Paulo: Atual Editora, 2005. FREIRE, Paulo. Pedagogia da autonomia: saberes necessários à prática educativa. 31. ed. São Paulo: Paz e Terra, 2005

HOFFMANN, Jussara. Avaliação mediadora. São Paulo: Cortez, 1994

LIMA, Maria S. C.; SILVA, Silvina P. O estágio docente numa perspectiva interdisciplinar. Fortaleza: UECE, 2004

LIRA, A.K e BRANDÃO, J. Matemática e deficiência visual. Fortaleza: Edições UFC, 2013.

LUCKESI, Cipriano C. Avaliação da aprendizagem escolar. 8. ed. São Paulo: Cortez, 1994.

LUDKE, Menga. Pesquisa em educação: abordagens qualitativas. 6. impr. São Paulo: EPU, 2001.

MAGALHÃES, E. B Vivências e convivências coma deficiência visual: relatos e práticas de profissionais/ [organizador] Jorge Brandão São Paulo. Scortecci, 2011.

PERRENOUD, Philip. Avaliação. São Paulo: Artmed, 1999.

VAN HIELE, P. Structure and insight: a theory of mathematics education. Orlando: Academic Press, 1986.

VYGOTSKY, L. S. A formação social da mente. São Paulo: Martins Fontes, 1988.

Como Citar esse artigo (ABNT):

MAGALHÃES, Elizângela B.; TORRES, Cícero Magérbio G.; BRANDÃO, Jorge C. Estudo de Congruências com Discentes Cegos: Uma Abordagem envolvendo a Sequência FEDATHI e o Método Van Hiele. Id on Line Revista de Psicologia, Julho de 2014, vol.8, n.23, p. 73-89. ISSN 1981-1179. 